\title{
A Simple Protocol to Effectively Manage Anal Fistulas with No Obvious Internal Opening
}

This article was published in the following Dove Press journal:

Clinical and Experimental Gastroenterology

\author{
Pankaj Garg (iD) ${ }^{1,2}$ \\ Baljit Kaur ${ }^{3}$ \\ Konica Singla ${ }^{2}$ \\ Geetha R Menon ${ }^{4}$ \\ Vipul D Yagnik (iD)
}

'Department of Colorectal Surgery, Indus International Hospital, Mohali, India;

${ }^{2}$ Department of Colorectal Surgery, Garg Fistula Research Institute (GFRI), Haryana, India; ${ }^{3}$ Department of Radiology, SSRD Imaging Centre, Chandigarh, India;

${ }^{4}$ Department of Biostatistics, Indian Council of Medical Research, New Delhi, India; ${ }^{5}$ Department of Surgical

Gastroenterology, Nishtha Surgical Hospital and Research Centre, Patan, Gujarat, India
Correspondence: Pankaj Garg

Garg Fistula Research Institute (GFRI), H. no- 1042, Sector-15, Panchkula, Haryana, |34 | |3, India

Fax +919501522000

Email drgargpankaj@yahoo.com
Purpose: In some anal fistulas, the internal/primary opening cannot be located even after examination and assessment on MRI or transrectal ultrasound. The efficacy of a simple new protocol to manage such therapeutically challenging fistulas was tested.

Patients and Methods: All anal fistula patients operated consecutively over 7 years were included in the study. A simple two-step protocol was followed for fistulas in which the internal opening was not locatable after clinical examination and MRI assessment. First, the MRI was reassessed. The site where the fistula was closest to the internal sphincter was noted. It was assumed that the internal-opening was located at that position and the fistula was treated accordingly. Second, in horseshoe anal fistulas with no apparent internal opening, it was assumed that the internal opening was located in the midline. Low fistulas were treated by fistulotomy and high fistulas by a sphincter-sparing procedure. Incontinence was evaluated by objective incontinence scores (Vaizey scores).

Results: A total of 757 patients were operated (median follow-up-33 months). Of these, 57 patients were excluded due to short or inadequate follow-up. In 154/700 (22\%) patients, the internal opening could not be located while in 546/700 (78\%), the internal opening was found. Both the groups were similar in all parameters. In the "internal-opening found" group, the fistula healed completely in 486/546 (89\%) and in the 'internal-opening not found group', the fistula healed in 140/156 (90.9\%) $(\mathrm{p}=1.01)$. The objective continence scores did not change significantly after surgery in both the groups.

Conclusion: This new protocol seems effective as a high cure rate could be achieved in 'internal-opening not found' fistulas which was comparable to fistula healing in the 'internalopening found' group.

Keywords: anal fistula, internal opening, horseshoe, MRI, recurrence, fistula-in-ano

\section{Introduction}

Complex anal fistula treatment is difficult as there is a significant risk of incontinence and the recurrence rate is quite high. There are several reasons for the high recurrence rate in complex anal fistulas which include the inability to manage high tracts, missed tracts, not finding the internal opening (IO) accurately, presence of multiple tracts, inadequate treatment of associated pathology like Crohn's disease, tuberculosis, etc. Among these reasons, inaccurate or inability to find the internal opening is the most important reason leading to recurrence of fistula. ${ }^{1-3,}$ Also, most of the prevalent procedures [such as advancement flap, ${ }^{4}$ LIFT (Ligation of Intersphincteric Fistula Tract), ${ }^{5}$ VAAFT (Video Assisted Anal Fistula Treatment), ${ }^{6}$ AFP (Anal Fistula Plug), ${ }^{7}$ fibrin glue, ${ }^{4}$ OTSC (Over-TheScope-clip), ${ }^{8}$ etc.] target or attempt to close the IO. Therefore, the inability to 
locate the IO accurately would make it difficult to even perform many of these procedures.

With the emergence of modern radiological techniques like transrectal ultrasound and MRI, the accuracy of locating the IO has increased. ${ }^{9}$ However, despite these sophisticated radiological techniques, there would still be a large number of cases in which it is difficult to determine the exact position of the IO. ${ }^{10}$ It is quite challenging to manage such fistulas.

The anal fistulas where the IO was not locatable by clinical examination and MRI assessment were managed by a simple protocol. This was not a new scheme but an assimilation of existing knowledge in an innovative way to create an effective protocol to manage these therapeutically difficult fistulas. To our knowledge, these themes have never been evaluated before in any study as there is no literature available which delineates management of fistulas with non-locatable IO.

In this study, the treatment success rate in anal fistulas where the IO was not locatable was compared to the outcome of fistulas in which the IO was found.

\section{Patients and Methods}

Patients of anal fistula managed surgically at a single center by the same surgeon (PG) between April 2013 to January 2020 were prospectively enrolled in the study. Approval was granted by the Indus International HospitalInstitute Ethics Committee (IIH-IEC) and written consent was taken from every patient. The patients were informed about the purpose of the study, and that the study was conducted in accordance with the Declaration of Helsinki.

Patients in whom the internal opening could not be located were identified. The internal-opening was labelled as 'non-locatable' when the following four steps could not determine the position of the internal opening (Figure 1):

1. Clinical examination before surgery - A gentle digital rectal examination was done and the point of maximum induration was felt.

2. Examination of patient on operating table under anesthesia (EUA) - A gentle examination of the rectum was done to assess the site of maximum induration and an attempt was made to detect the internal opening by visually inspecting the anal canal.

3. Under anesthesia, a colored solution (povidoneiodine solution in this study) was injected through one of the external (secondary) openings and its egress was observed from the anal canal to detect the internal opening.
4. Assessment of fistula on MRI: MRI was a useful modality and it could locate the internal opening quite accurately in most cases (Figures 2-4).

\section{Management of Fistulas in Which Internal Opening (IO) Could Not Be Found Protocol Followed}

The fistula cases where the IO was not locatable by the above four steps were labelled as 'IO-not found' and the following two-step protocol was deployed (Figure 1):

1. The MRI scan was analyzed in detail again by the surgical team. The site where the fistula tract reached nearest to the internal sphincter was noted. That was assumed to be the location of the IO and the fistula was managed accordingly. For example, in cases with posterior fistula where the fistula tract could be seen extending up to the internal anal sphincter (IAS) in the posterior midline but not reaching the mucosa of the anus (the site of the IO uncertain) (Figure 5), it was assumed that the IO was present in the posterior midline and the fistula was managed accordingly. A similar assumption was made for fistulas in other locations (Figure 6).

2. In horseshoe fistulas with non-locatable IO, the above-mentioned step was not helpful as a horseshoe fistula touches the sphincter complex at multiple places (along the horseshoe tract in a circumferential manner) and may not touch the IAS at one place. So, in horseshoe fistula, the fistula was managed to assume that the IO was in the midline in these cases (in posterior horseshoe fistulas, the IO was assumed to be in the posterior midline, while in anterior horseshoe fistulas, it was assumed to be in the anterior midline) (Figure 7).

The details of the fistulas were entered in a data spreadsheet for every patient. Apart from demographic details (Table 1), the following data were entered - the history of previous operations for anal fistula, the objective incontinence scores before and after surgery, any associated abscesses, single or multiple tracts, horseshoe tracts (Tables 2 and 3), suprasphincteric or supralevator tracts, whether the IO could be accurately identified or not, and whether the fistulas were low (fistula involved $<1 / 3$ of the external sphincter) or high [fistula involved $>1 / 3$ of the external anal sphincter (EAS)]. 
--Clinical Examination - Preoperative

- Intraoperative

(Examination under anesthesia)

-- Injection of Colored solution from External opening to note its egress from Internal opening (Intraoperative)

\section{-- MRI assessment}

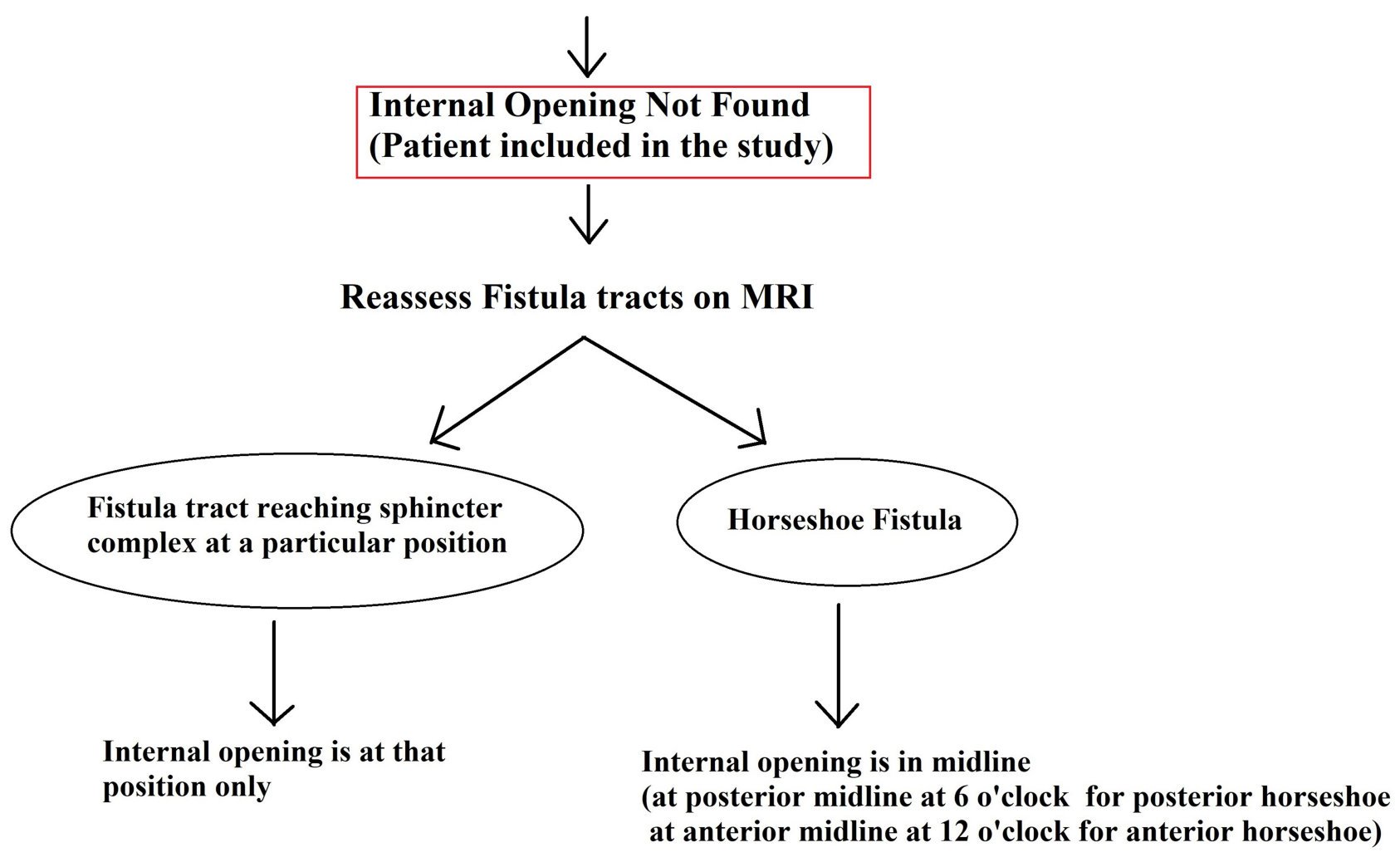

Figure I The protocol to manage anal fistulas in which the internal opening was not found by conventional methods and MRI.

The surgical procedure was decided according to the extent of the EAS involvement. Low fistulas were treated by fistulotomy and high fistulas were managed by a sphincter-sparing procedure. Since the surgeon was experienced and well versed with the TROPIS (transanal opening of intersphincteric space) technique, so this was chosen as the sphincter-sparing procedure. ${ }^{11-15}$

\section{TROPIS (Transanal Opening of Intersphincteric Space) Procedure}

TROPIS is a logical modification of the LIFT procedure in which, instead of simply ligating the intersphincteric tract, the intersphincteric portion of the fistula tract is laid open and deroofed into the anal canal. ${ }^{11}$ In fistulas in which the IO was located, the direction and length of the intersphincteric portion of the fistula tract from the internal opening was carefully noted. From the IO, a curved artery-forceps was inserted into this intersphincteric portion of the fistula tract. ${ }^{11}$ Using electrocautery, the tissue (mucosa and the internal sphincter) overlying the artery-forceps was cut so that the intersphincteric portion of the fistula tract was laid open into the anal canal. In supralevator fistulas, the superior coursing fistula branch in the intersphincteric plane was also laid open into the anal canal. ${ }^{11,12}$

Once the intersphincteric portion of the fistula was laid open into the anal canal, then an incision was made in the 

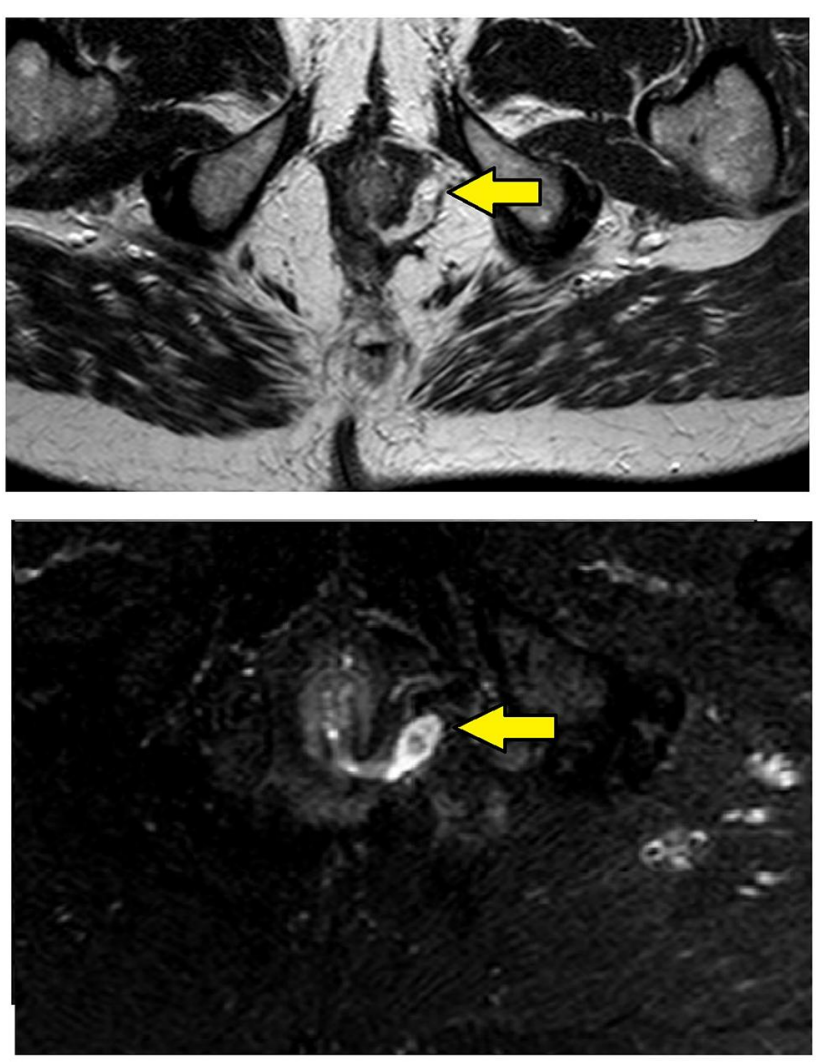

Figure $2 \mathrm{MRI}$-axial sections in a 56-year-old male with transsphincteric fistula at 3 o'clock position and the internal opening in the anal canal at the posterior midline. Upper panel - T2, lower panel - Short tau inversion recovery (STIR) (Yellow arrows are showing fistula tract).

intersphincteric groove in the skin at the radial position of the internal opening and the intersphincteric space distal (inferior) to the internal opening was laid open by a vertical incision (Figure $8 \mathrm{D}$ and $\mathrm{F}$ ). This was done so that any fluid discharge or collection in the laid-open intersphincteric portion of the fistula tract could drain easily out of the anal canal. Moreover, it created a saucershaped wound [Figure 8D and F, Figure 9F, Figure 10C] which led to better healing by secondary intention.

In cases where the IO was not locatable, the site where the external portion of the fistula tract reached closest to the sphincter complex was identified on the MRI scan. As per the protocol, this was assumed to be the location of the IO. At this location, an incision was made in the perianal skin over the intersphincteric groove and the intersphincteric space laid open by a vertical incision. Once the intersphincteric space was laid open, the additional intersphincteric tracts or intersphincteric horseshoe tracts were also laid open in continuity.

The transsphincteric tracts in the ischiorectal fossa could be managed in several ways (curettage, surgical excision, fixcision, laser ablation, etc.). ${ }^{12}$ In the present
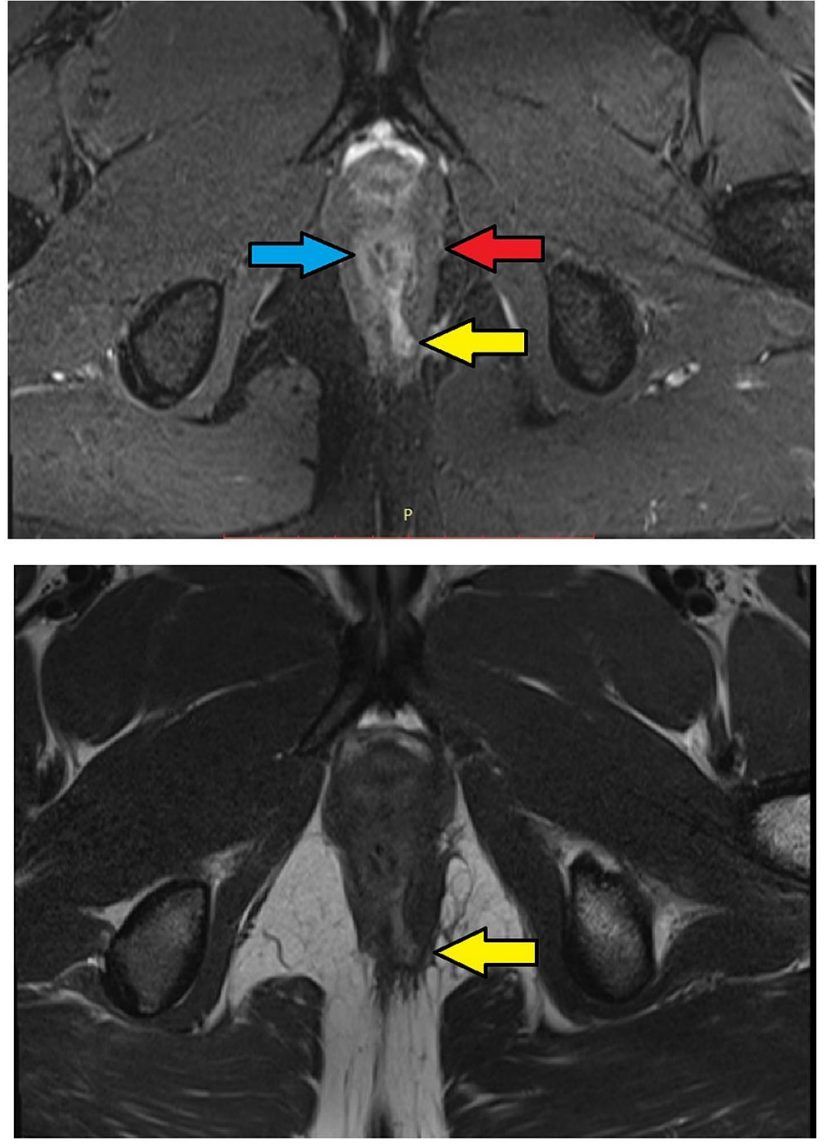

Figure $3 \mathrm{MRI}$-axial sections in a 30-year-old male with low transsphincteric anal fistula at 5 o'clock position. The tract traverses through both external and internal anal sphincters and opens in the anal canal at the posterior midline position. Upper panel - T2, lower panel - STIR (Yellow arrows are showing fistula tract, blue arrow are showing the internal sphincter, red arrow are showing the external sphincter).

study, the external tracts were curetted and cleaned from the external (secondary) openings and a tube (abdominal drainage tube) was inserted into the transsphincteric tracts up to the level of the EAS and was sutured to the skin. Once the wound inside the rectum had healed by secondary intention, the tube (or tubes in case of multiple tracts) was removed. Thus, without cutting or damaging the EAS, the tracts on either side were dealt with - the tract inner to the EAS (intersphincteric tract and IO) from inside the rectum, and tracts outside the EAS (tracts in ischiorectal fossa) from outside through the external openings. ${ }^{11-15}$

Incontinence was assessed objectively both before and after surgery (long term follow-up) by incontinence scoring (Vaizey scores). ${ }^{16}$ In Vaizey scoring, seven parameters are assessed. ${ }^{16}$ These are incontinence to gas, liquid stools and solid stools, whether a pad is needed, alteration in lifestyle, need to take medicines to increase stool consistency, and ability to hold defecation for 15 minutes. 


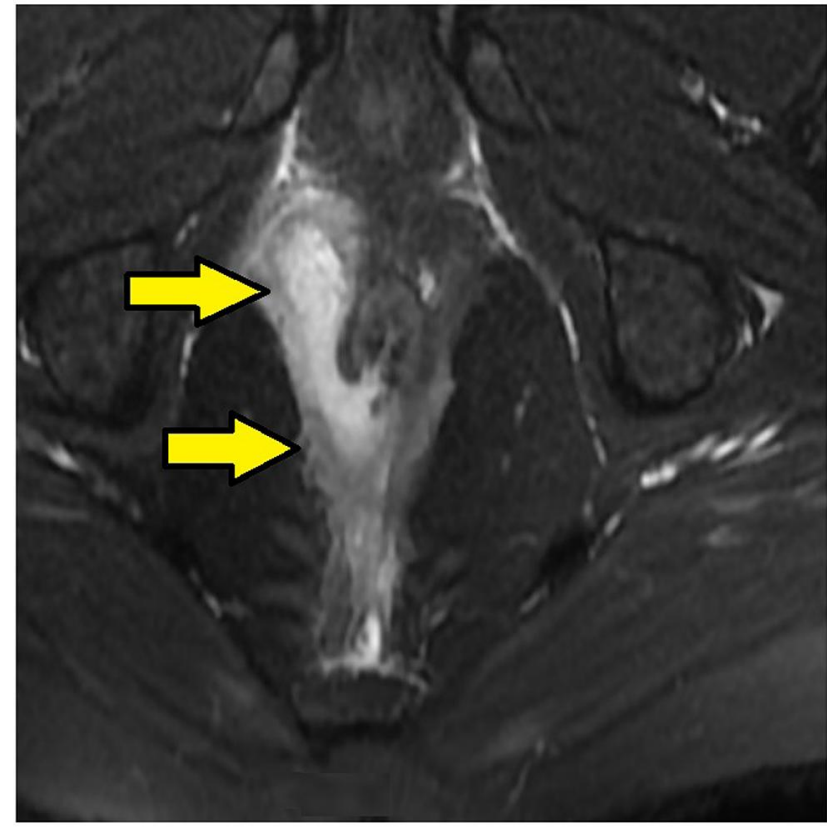

Figure $4 \mathrm{MRI}$-axial-STIR sections in a 26-year-old male with high intersphincteric fistula from Ilo'clock to posterior midline piercing the internal sphincter and opening in the anal canal at the posterior midline. Upper panel - T2, lower panel - STIR (Yellow arrows are showing fistula tract).

A score of 24 represents complete incontinence and perfect continence has a score of zero. ${ }^{16}$ The Vaizey scoring system was used as it is relatively comprehensive.

The patients were followed-up on monthly visits to the clinic. During the follow-up visits, clinical examination was done and continence evaluated. Once healing was complete, the post-operative MRI was done to corroborate the clinical healing. This was not done as a protocol but only in the patients who wanted to ensure radiological healing along with clinical healing. Subsequently, long-term follow-up was done telephonically or by online messaging and the latest status was updated. The patients who could not be contacted and whose long-term status could not be ascertained were deemed lost to follow-up.

The fistula was taken as healed when pus discharge from the anus and all the tracts stopped completely. Continuous or persistent discharge of pus from even a single tract was considered a failure of treatment.

\section{Statistical Analysis}

The StatsDirect software for statistics was used (StatsDirect Ltd Merseyside, UK). Fisher's exact test or chi-squared test was used to compare categorical variables. For normally distributed data, Student's $t$-test was used for
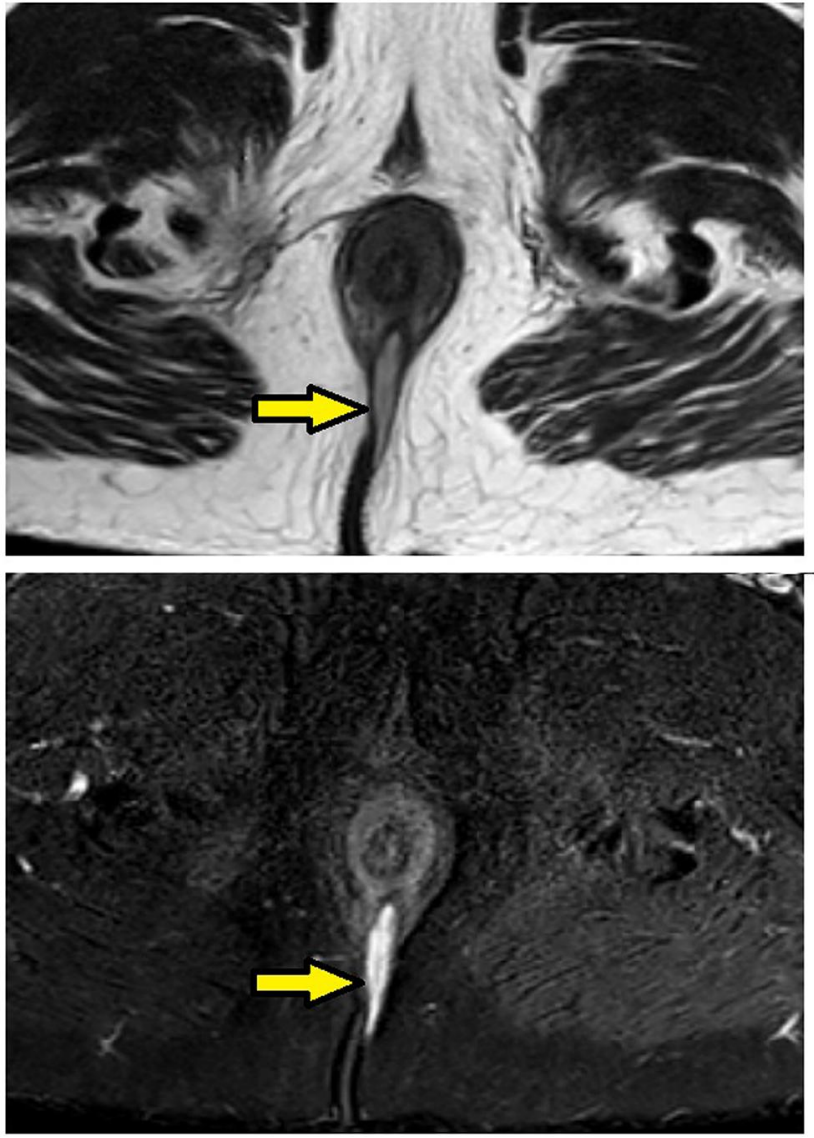

Figure $5 \mathrm{MRI}$-axial-STIR sections in a $5 \mathrm{I}$-year-old male with low transsphincteric fistula at posterior midline position. The tract is penetrating the external but not the internal sphincter and is not seen opening in anal canal. (Yellow arrows are showing fistula tract).

the continuous variables in two samples. For samples more than two, ANOVA test was used. In data that were not normally distributed, for paired samples, Wilcoxon signedrank test was used and for unpaired samples, MannWhitney U-test was used. The cut-off point for significance was set at $\mathrm{p}<0.05$.

\section{Results}

A total of 757 patients were operated with a follow-up ranging from 4 to 84 months (median -33 months). Of these, 57 patients were excluded as there was short or inadequate follow-up and 700 were included in the analysis. Both the groups (IO-found and IO-not found) were comparable in sex, age, fistula characteristics (recurrent fistulas, horseshoe fistulas, associated abscess or multiple tracts), fistula type (intersphincteric, transsphincteric, supralevator or suprasphincteric fistula) or complexity of fistula (St James's University Hospital classification) (Table 1). 

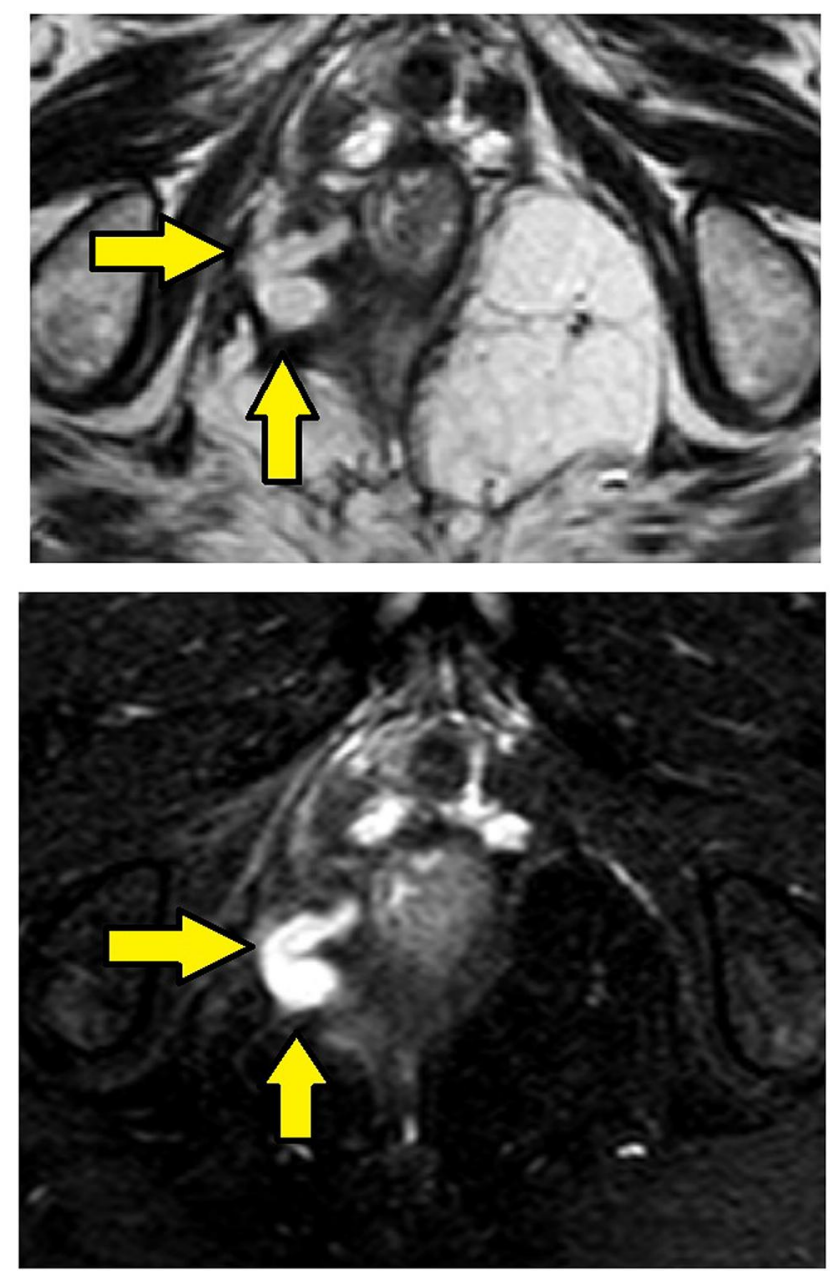

Figure $6 \mathrm{MRI}$-axial sections in a 52 year-old-male with high transsphincteric fistula in the right ischiorectal fossa with fistula tract reaching the external sphincter at 9 o'clock but not piercing external and internal sphincters and not opening in anal canal. Upper panel - T2, lower panel - STIR (Yellow arrows are showing fistula tract).

In $154 / 700(22 \%)$ patients, the IO could not be located after examination and MRI assessment (Figures 5-7). In $546 / 700$ (78\%), the IO could be located (Figures 2-4).

The procedures performed (fistulotomy and TROPIS) were also comparable in both the groups (Table 2). The fistula healed completely in $486 / 546(89 \%)$ in the IOfound group and 140/154 (90.9\%) in the IO-not found group $(\mathrm{p}=0.55)$ (Table 2). The mean incontinence scores and number of patients with incontinence (gas, liquid, solid and urge incontinence) before surgery and after surgery were also not significantly different in both groups (Table 2). The change (difference) in post-operative and pre-operative continence scores was also similar in both the groups ( $\mathrm{p}=0.28$, Mann Whitney U-test) (Table 2).

There were 108 horseshoe fistula and 438 non-horseshoe fistulas in the IO-found group ( $\mathrm{n}=546)$ (Table 3). In the
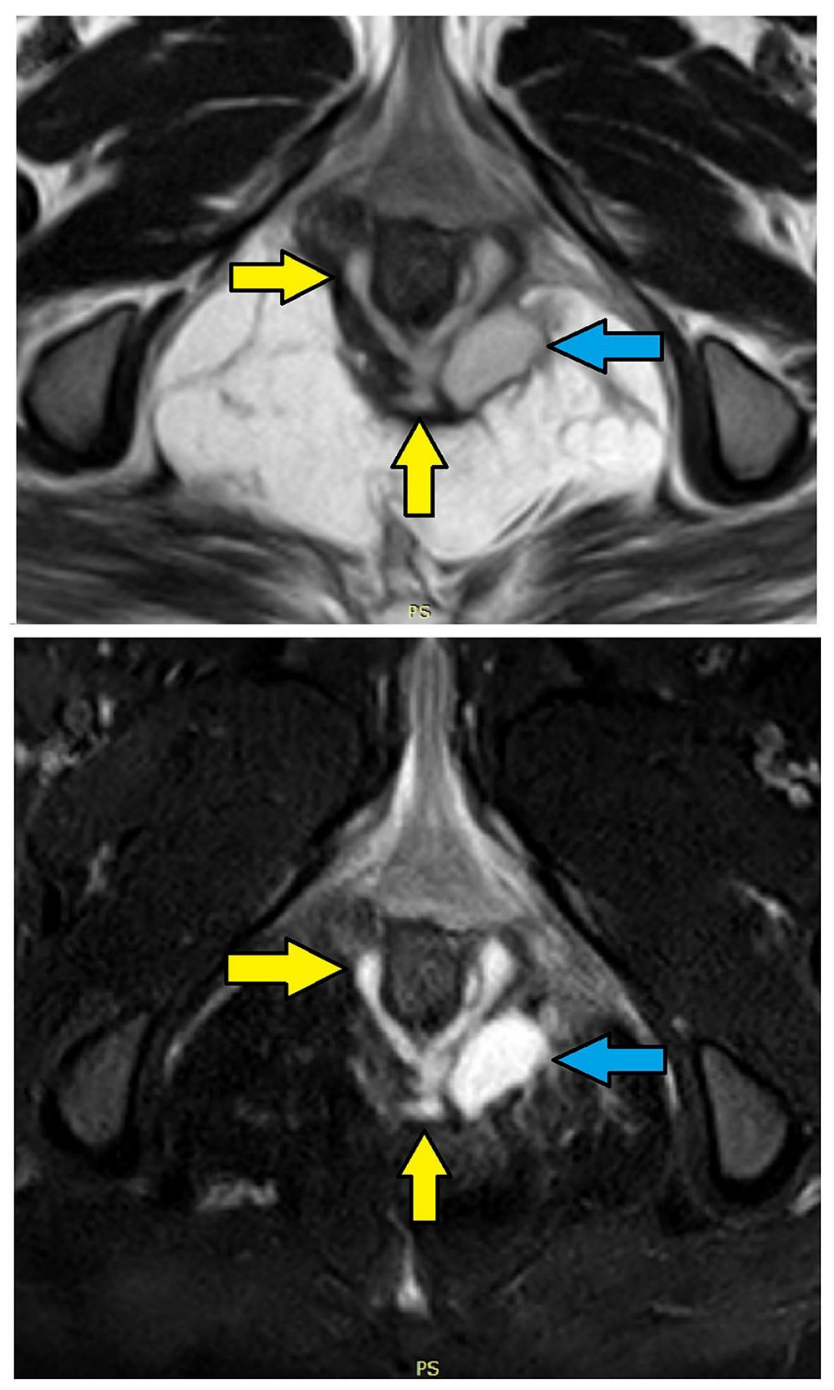

Figure $7 \mathrm{MRI}$ - axial sections in a 28-year-old female with posterior intersphincteric horseshoe fistula and high transsphincteric abscess in the left ischiorectal fossa with NO clear internal opening. Upper panel - T2, lower panel - STIR (Yellow arrows are showing fistula tract, blue arrows are showing high transsphincteric abscess).

horseshoe group ( $\mathrm{n}=108), 105 / 108(97.3 \%)$ fistulas had openings in the midline (posterior-6 o'clock or anterior-12 o'clock) and only 3 (2.7\%) horseshoe fistulas had openings in the lateral position ( $<<0.00001$, significant) (Table 3 ). The healing rate of horseshoe fistulas in both IO-found and IOnot found groups was similar (82/108, $75.9 \%$ vs $17 / 85,85 \%$, respectively, $\mathrm{p}=0.56$, not significant) (Table 2 ).

\section{Discussion}

This study highlights a few important findings. This is the largest study in which the incidence (22\%) of fistulas with 'internal opening (IO) not found' has been reported. This is also the first and the largest study with a long-term follow-up (median of 33 months) in which the definitive 
Table I Patient Parameters

\begin{tabular}{|c|c|c|c|}
\hline Fistula Parameters & $\begin{array}{l}\text { Internal Opening } \\
\text { Found }(n=546)\end{array}$ & $\begin{array}{l}\text { Internal Opening Not } \\
\text { Found }(n=154)\end{array}$ & $\begin{array}{l}\text { Test of Significance (Fisher's test/t-test) } \\
\text { P<0.05=Significant }\end{array}$ \\
\hline $\begin{array}{l}\text { Male/Female } \\
\text { Age (years) } \\
\text { Recurrent fistula } \\
\text { Associated Abscess } \\
\text { Multiple tracts } \\
\text { Horseshoe tract }\end{array}$ & $\begin{array}{l}468 / 78 \\
38.3 \pm 10.5 \\
282(51.6 \%) \\
133(24.4 \%) \\
328(60.1 \%) \\
108(19.8 \%)\end{array}$ & $\begin{array}{l}129 / 25 \\
37.8 \pm 11.9 \\
80(51.9 \%) \\
49(31.8 \%) \\
76(49.4 \%) \\
20(12 \%)\end{array}$ & $\begin{array}{l}P=0.52 \\
P=0.99 \\
P=1.0 . \\
P=0.07 \\
P=0.06 \\
P=0.06\end{array}$ \\
\hline $\begin{array}{l}\text { Fistula Type } \\
\text { Intersphincteric } \\
\text { Transsphincteric } \\
\text { Supralevator }+ \\
\text { Suprasphincteric fistula }\end{array}$ & $\begin{array}{l}21 \mathrm{II}(38.6 \%) \\
263(48.2 \%) \\
72(13.2 \%)\end{array}$ & $\begin{array}{l}59(38.3 \%) \\
80(52.0 \%) \\
15(9.7 \%)\end{array}$ & $P=0.27$ \\
\hline $\begin{array}{l}\text { Fistula Complexity } \\
\text { St James's University } \\
\text { Hospital (SJUH) } \\
\text { Classification }\end{array}$ & $\begin{array}{l}\text { Grade I - II } 4 \text { (20.9\%) } \\
\text { Grade II - } 97(\text { (I7.7\%) } \\
\text { Grade III - } 49 \text { (9.0\%) } \\
\text { Garde IV - } 2 \text { I } 4(39.2 \%) \\
\text { Grade V - } 72(\text { (I3.2) }\end{array}$ & $\begin{array}{l}\text { Grade I-20 (I3.0\%) } \\
\text { Grade II -39 (25.3\%) } \\
\text { Grade III - } 2 \text { I (I3.6\%) } \\
\text { Garde IV - } 59(38.4 \%) \\
\text { Grade V - I5 (9.7\%) }\end{array}$ & $P=0.18$ \\
\hline Fistula Complexity & $\begin{array}{l}\text { Low fistulas }=351(64.3 \%) \\
\text { High fistulas }=195(35.7 \%)\end{array}$ & $\begin{array}{l}\text { Low fistulas }=103(66.9 \%) \\
\text { High fistulas }=51(33.1 \%)\end{array}$ & $P=0.56$ \\
\hline
\end{tabular}

Notes: Low fistulas $-<1 / 3$ of the external sphincter involved; High $->1 / 3$ of the external sphincter involved.

management of fistulas with 'IO not found' has been discussed in detail.

Out of 700 operated fistula patients, it was found that the IO could not be determined in $22 \%$ of patients. The most significant finding was that it was possible to achieve a high cure rate $(91 \%)$ in such fistulas (IO not found). Moreover, the healing rate and change in incontinence scores in these fistulas were similar to the healing rates in the patients in whom the IO could be identified accurately ('IO found' group). Healing and incontinence rates are the two most important parameters in fistula management. Thus, these results corroborate the efficacy of the protocol assessed in this study (Figure 1). Both the steps of the protocol are logical and there is nothing novel about them. However, utilizing these steps as a protocol to manage fistulas without locatable internal opening has been done for the first time in this study.

These findings strongly validate the concept that if a portion of the fistula tract reaches a point near the internal sphincter on MRI but the IO cannot be determined by any of the known methods, then it may be assumed to be at that location only and the fistula accordingly managed (Figures 5-7). This also seems logical as the IO is expected to be located at the place at which the fistula reaches closest to the sphincter complex. It is highly unlikely that a fistula tract reaches up to a position near the sphincter complex, say posterior midline, and then opens in the anorectum at some other location. Though this exception is theoretically possible, the results of the study suggest that it is highly unlikely. Moreover, such an exception would be detected by MRI which has a very high sensitivity to pick up fistula tracts. Needless to say, the application of this concept requires accurate interpretation and optimum utilization of MRI. It would be pertinent to mention that transrectal ultrasound (TRUS) or endoanal ultrasound (EUS) would also be a useful adjunct in this. ${ }^{17,18}$ TRUS can supplement the findings of MRI. ${ }^{19-21}$ The advantages of EUS are that it can be repeated easily and unlike MRI, it can also be done intraoperatively.

In the 'IO found' group ( $\mathrm{n}=546)$, there were 108 horseshoe fistulas. In almost all these horseshoe fistulas (97.3\%) the IO was in the midline (in posterior horseshoe anal fistulas, the IO was posterior midline and in horseshoe anal fistulas, it was anterior midline) (Table 3). When this concept was applied to the horseshoe fistulas in 'IOnot found' group ( $\mathrm{n}=20$, Tables 1 and 2$)$, the healing rate was $85 \%(17 / 20)$. This was comparable to the healing rate of the horseshoe fistulas in 'IO found' group (75.9\%) ( $p=0.56$, not significant) (Table 2 ). These findings corroborate the efficacy of the second step of the protocol. 
Table 2 Results

\begin{tabular}{|c|c|c|c|}
\hline Fistula Parameters & $\begin{array}{l}\text { Internal Opening Found } \\
(n=546)\end{array}$ & $\begin{array}{l}\text { Internal Opening Not } \\
\text { Found }(n=154)\end{array}$ & $\begin{array}{l}\text { Test of Significance (Fisher's } \\
\text { test/t-test) } \\
\text { P<0.05=Significant }\end{array}$ \\
\hline Procedure performed (Fistulotomy) & $326(59.7 \%)$ & 89 (57.8\%) & $P=0.71$ \\
\hline Sphincter-sparing procedure (TROPIS) & $220(40.3 \%)$ & $65(42.2 \%)$ & \\
\hline Fistula Healing-Overall & $486(89.0 \%)$ & 140 (90.9\%) & $P=0.55$ \\
\hline Fistula Healing-Horseshoe fistulas & $82 / 108(75.9 \%)$ & $17 / 20(85 \%)$ & $P=0.56$ \\
\hline \multirow[t]{3}{*}{$\begin{array}{l}\text { Incontinence Scores (Vaizey } \\
\text { scores) (Mean) }\end{array}$} & $\begin{array}{l}\text { Pre-Op } \\
0.075 \pm 0.53\end{array}$ & $\begin{array}{l}\text { Pre-Op } \\
0.013 \pm 0.11\end{array}$ & $P=0.56$ \\
\hline & $\begin{array}{l}\text { Post-Op } \\
0.132 \pm 0.62\end{array}$ & $\begin{array}{l}\text { Post-Op } \\
0.111 \pm 0.54\end{array}$ & $P=0.13$ \\
\hline & $\begin{array}{l}\text { Difference in before surgery } \\
\text { (Pre-op) and after surgery } \\
\text { (Post-op) scores } \\
0.051 \pm 0.74\end{array}$ & $\begin{array}{l}\text { Difference in before surgery } \\
\text { (Pre-op) and after surgery } \\
\text { (Post-op) scores } \\
0.090 \pm 0.52\end{array}$ & $P=0.28$ \\
\hline \multirow[t]{9}{*}{ Incontinence (number of patients) } & Pre-Op $(n=17)$ & Pre-Op $(n=2)$ & $P=0.27$ \\
\hline & Gas-10 & Gas-2 & \\
\hline & Liquid-5 & Liquid-0 & \\
\hline & Solid-I & Solid-0 & \\
\hline & Urge-I & Urge-0 & \\
\hline & Post-Op $(n=3 \mid)$ & Post-Op (n=8) & $P=1.0$ \\
\hline & Gas-16 & Gas-5 & \\
\hline & Liquid-6 & Liquid- I & \\
\hline & Solid-2 Urge-7 & Solid-0 Urge-2 & \\
\hline
\end{tabular}

Table 3 Internal Opening Location in Horseshoe Fistula in IO-Found (Internal Opening Found) Group $(n=546)$

\begin{tabular}{|l|l|l|l|}
\hline $\begin{array}{l}\text { Location of Internal } \\
\text { Opening }\end{array}$ & $\begin{array}{l}\text { Horseshoe Fistula } \\
(\mathbf{n}=108)\end{array}$ & $\begin{array}{l}\text { Non-Horseshoe Fistula } \\
\mathbf{( n = 4 3 8 )}\end{array}$ & Test of Significance P<0.05= Significant \\
\hline Posterior midline & $87(80.6 \%)$ & $227(5 I .8 \%)$ & $\mathrm{P}=0.0000 \mathrm{I}$ (significant, Fisher's exact test) \\
Anterior Midline & $18(16.7 \%)$ & $\mathrm{I} 67(38.1 \%)$ & $\mathrm{P}=0.0000 \mathrm{I}$ (significant, Fisher's exact test) \\
Lateral & $3(2.7 \%)$ & $44(10.5 \%)$ & $\mathrm{P}=0.012$ (significant, Fisher's exact test) \\
\hline
\end{tabular}

The reason for the high incidence (22\%) of the 'IO not found' fistulas in the present study could be that the study was done in a referral center. The fistulas in which the IO is not found are difficult to treat. Hence, they are more often referred to specialized fistula centers. Therefore, it can be assumed that the incidence of anal fistulas with 'IOnot found' would be lower in the population.

The fistula healing rates in the 'IO found' and 'IO not found' groups were $89 \%$ and $90.9 \%$, respectively (Table 2 ). The high success rate could be because about twothirds of the fistulas were low and were safely managed with fistulotomy (Table 1). The latter procedure is associated with a success rate of $95-98 \%$ in high turn-over centers. ${ }^{22}$ In high fistulas, surgeons can perform any sphincter-saving procedure with which they are comfortable. Since, in this study, surgeon was well versed with the TROPIS procedure, this technique was performed exclusively. ${ }^{11,13}$

Several methods have been used to accurately locate the position of IO like Goodsall's rule, ${ }^{23}$ injection of hydrogen peroxide $\left(\mathrm{H}_{2} \mathrm{O}_{2}\right)$ through the external opening, ${ }^{24}$ anography, ${ }^{25}$ transrectal ultrasound (TRUS) or transperineal ultrasound (TPUS), ${ }^{9}$ hydrogen peroxide $\left(\mathrm{H}_{2} \mathrm{O}_{2}\right)$ enhanced transrectal ultrasound ${ }^{10}$ and MRI scan. ${ }^{26}$ It has been shown that Goodsall's rule is inaccurate and unreliable to assess the location of the $\mathrm{IO} .^{23}$ There was 

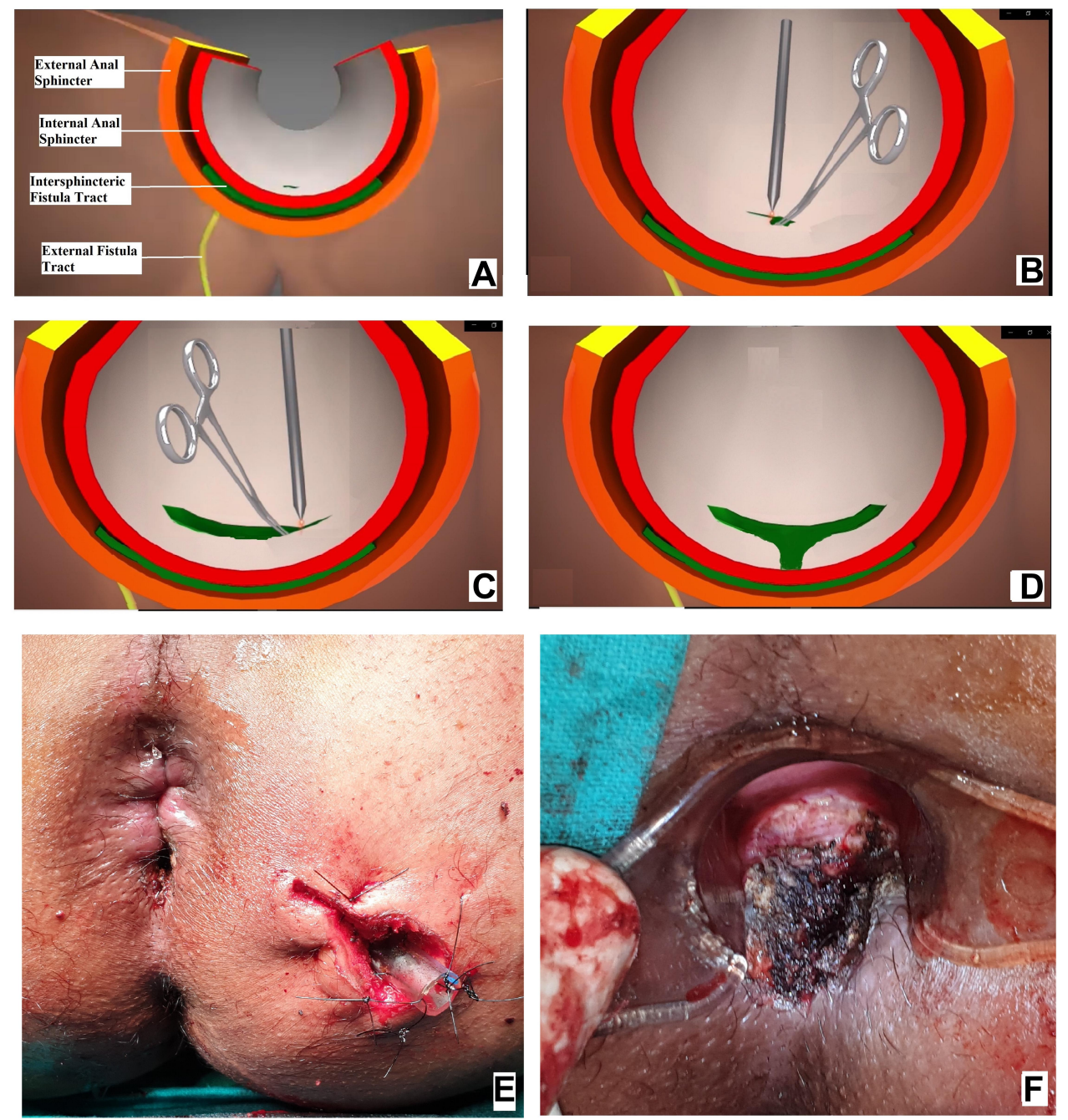

Figure 8 Intraoperative wound after TROPIS (transanal opening of intersphincteric space). (A) Schematic diagram of anal fistula and anal canal, (B) Schematic diagram showing the intersphincteric portion of the fistula tract (green colour) and an artery forceps inside the internal opening about to be laid open with electrocautery, (C) Schematic diagram showing the intersphincteric portion of the fistula tract laid open with electrocautery, (D) Intersphincteric space distal (inferior) to the internal opening laid open by a vertical incision, (E) Intraoperative photograph of a patient after a complete TROPIS procedure showing the TROPIS wound in the anal canal and a tube inserted in the tract in left ischiorectal fossa. The tube sutured to the skin with monofilament non-absorbable suture (2-0 nylon). (F) Intraoperative photograph showing the TROPIS wound in the anal canal.

only a $61.1 \%$ correlation between $\mathrm{H}_{2} \mathrm{O}_{2}$-enhanced transrectal ultrasound and surgical findings of the IO. ${ }^{10}$ Despite all these methods, the IO cannot be found in a proportion of patients (Figures 5-7). However, there are no protocols in the literature that guide the management of patients in whom the IO cannot be located after using conventional methods and advanced radiological techniques.

There are several possible reasons for not finding the IO on clinical examination and on injecting a colored liquid into the external opening. There could be blockage of the inflamed perianal glandular crypt by fecal material or swollen surrounding inflamed tissues. ${ }^{2}$ Over time, the IO may be closed by granulation tissue and, thus, difficult to identify. ${ }^{2}$ In such cases, a probe must not be forced but should be gently maneuvered. Forceful probing can lead to a rectal wall perforation and an iatrogenic fistula. ${ }^{2}$ Fistulas in which the IO is not found are very often labelled 'perianal sinuses'. However, this seems inappropriate because such 'sinuses' keeps on recurring at the same location and behave like a fistula. ${ }^{2}$ A true perianal sinus not communicating with the anorectum would usually be expected to close spontaneously as there is no repeated ingress of microbes from the gut. So, a case of a 'perianal sinus' that is not healing spontaneously or recurring at the same location should be treated as a case of "anal fistula with not clearly identifiable IO".

The need to properly manage anal fistulas in which the IO is not found cannot be overemphasized. The 
AXIAL

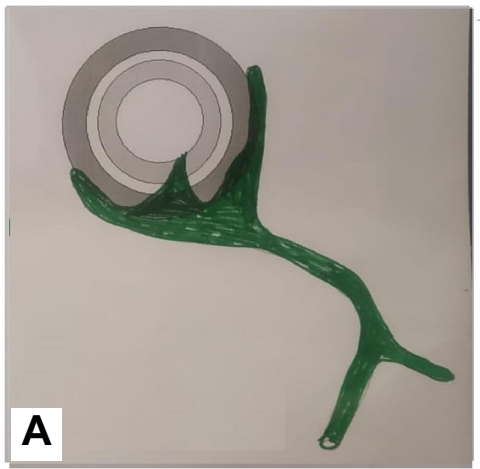

AXIAL (LOW)

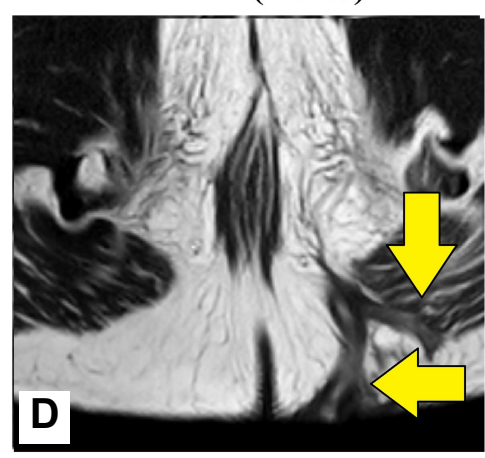

AXIAL (HIGH)

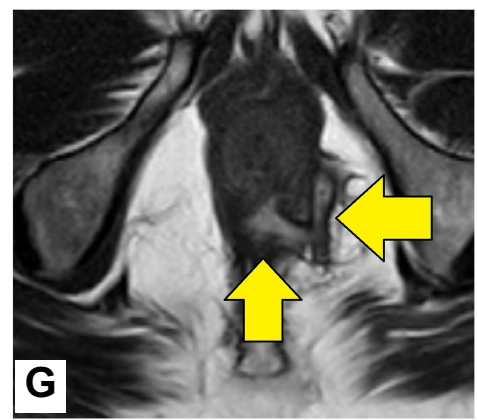

CORONAL

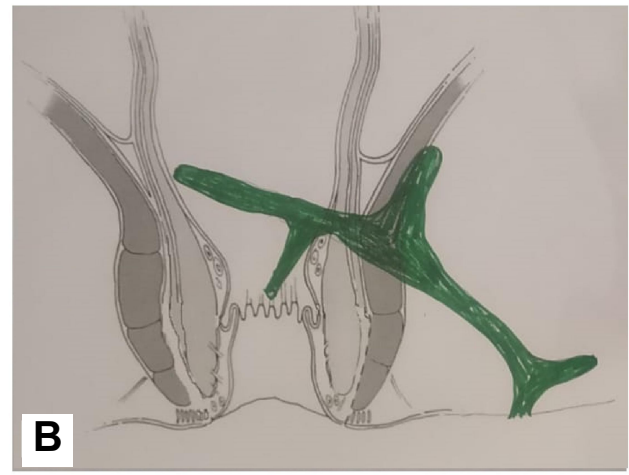

CORONAL (LOW)

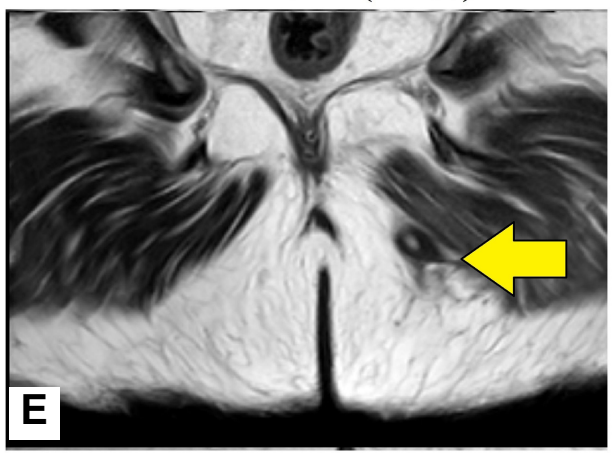

CORONAL (HIGH)

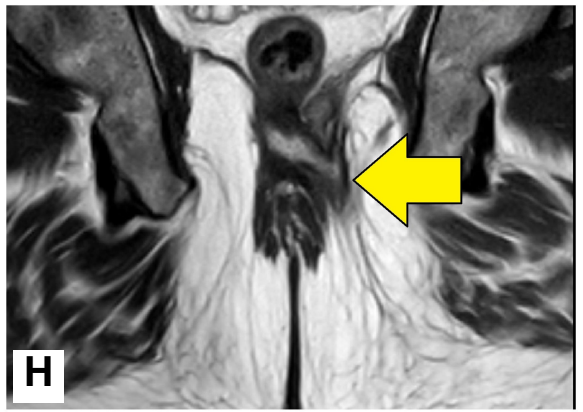

PRE-OPERATIVE

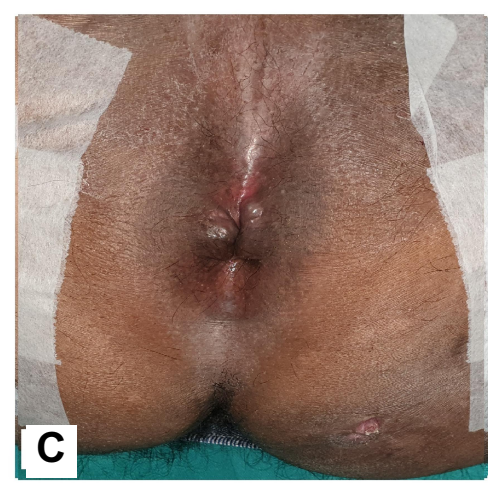

POST-OPERATIVE

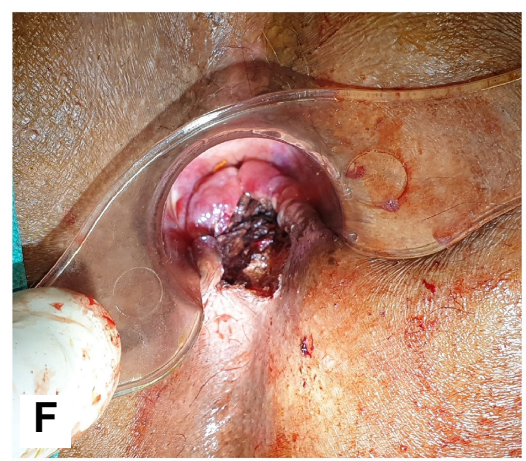

POST-OPERATIVE

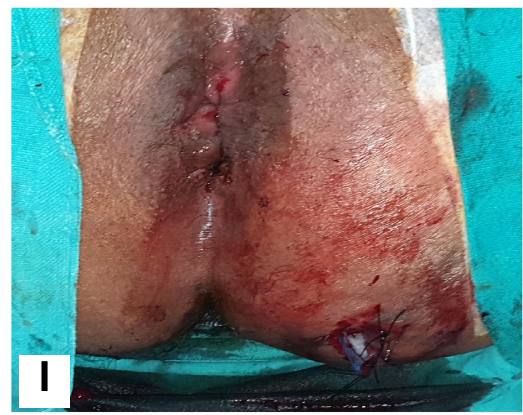

Figure 9 A 55-year-old male patient with a recurrent high transsphincteric anal fistula with multiple tracts. (A) Axial section (Schematic diagram), (B) Coronal section (Schematic diagram), (C) Pre-operative photograph (D) MRI-axial section-low level (T2), (E) MRI-coronal section-low level (T2), (F) Post-operative photograph showing TROPIS wound (laid open intersphincteric portion of the fistula tract) in the anal canal. (G) MRI-axial section-high level (T2), (H) MRI-coronal section-high level (T2), (I) Post-operative photograph showing the final picture (TROPIS wound in the anal canal) and a tube inserted in the tract in left ischiorectal fossa. The tube sutured to the skin with monofilament non-absorbable suture (2-0 nylon) (Yellow arrows are showing fistula tracts).

healing rate in such fistulas has been dismal. More than half of such operated anal fistula are at risk of recurrence. ${ }^{1}$ Another study showed that the relative risk (RR) of recurrence of the anal fistula was very high (20times) when the IO was not locatable against when the IO could be accurately located. ${ }^{2}$ A large meta-analysis, recently published, demonstrated that there were several risk factors that were responsible for the recurrence of anal fistulas. Amongst these factors, the inability to localize the IO was associated with the maximum risk. ${ }^{3}$ The study listed the various reasons responsible for fistula recurrence in the order of decreasing risk. Inability to locate the internal opening was associated with a RR of 8.54 , a trans-sphincteric high fistula was associated with RR of 4.77, presence of multiple tracts had a RR of 4.77, associated horseshoe tract had a RR of 1.92 and recurrent fistula were associated with RR of 1.52 of fistula recurrence. ${ }^{3}$ Against this background, this protocol could be of great use to manage such fistulas as has been corroborated by the results of the present study. 
AXIAL

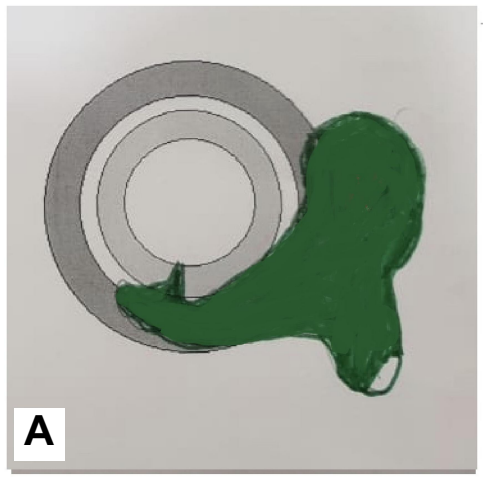

AXIAL

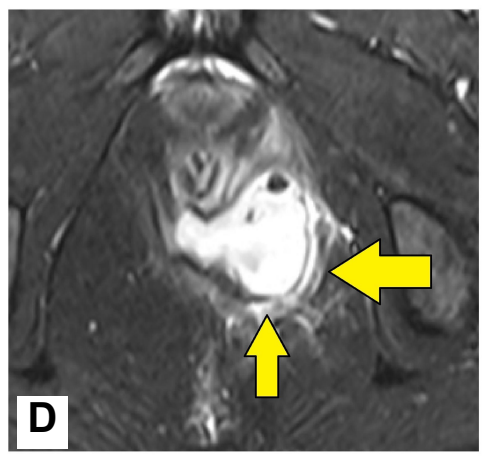

\section{CORONAL}

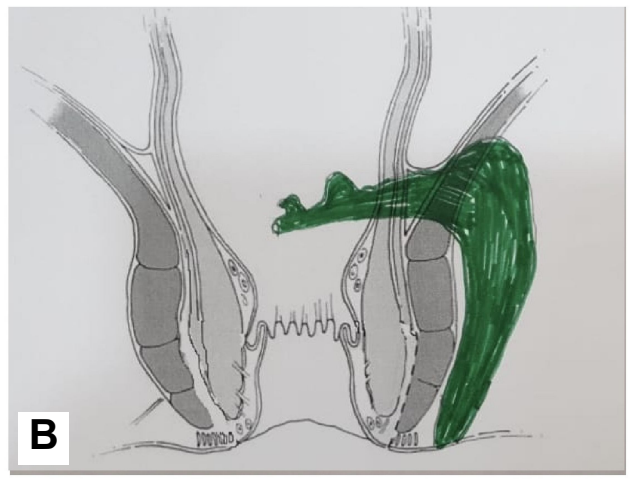

CORONAL

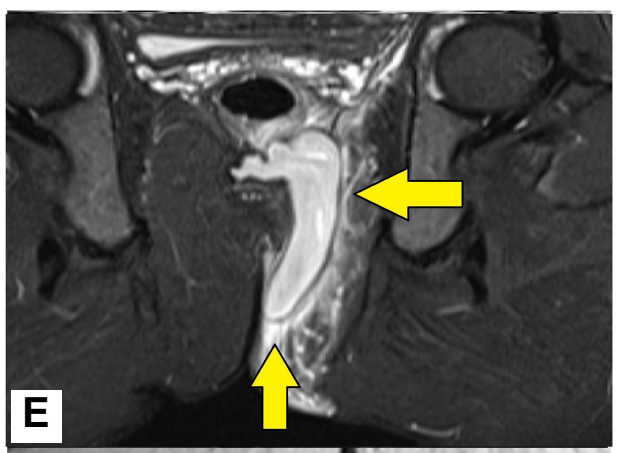

POST-OPERATIVE

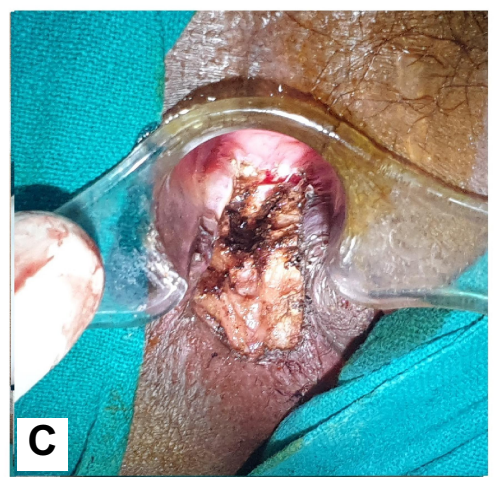

POST-OPERATIVE

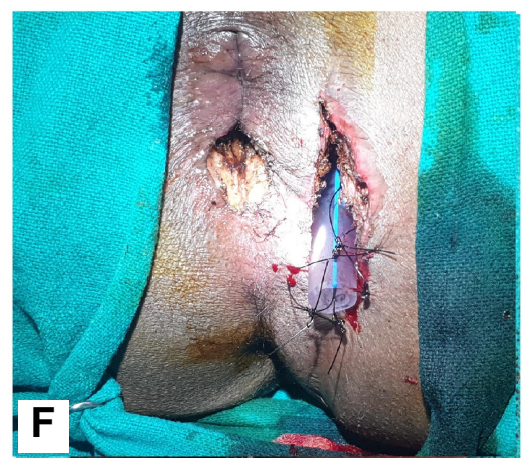

Figure 10 A 34-year-old male patient with a high horseshoe transsphincteric anal fistula and abscess. (A): Axial section (Schematic diagram), (B) Coronal section (Schematic diagram), (C) Post-operative photograph showing TROPIS wound (laid open intersphincteric portion of the fistula tract) in the anal canal. (D) MRI-axial section (STIR), (E) MRI-coronal section (STIR), (F) Post-operative photograph showing the final picture (TROPIS wound in the anal canal) and a tube inserted in the tract in left ischiorectal fossa. The tube sutured to the skin with monofilament non-absorbable suture ( $2-0$ nylon) (Yellow arrows are showing fistula tracts).

It is pertinent to note that the first step of the protocol requires an accurate and detailed assessment of MRI. Therefore, thorough knowledge of anorectal MRI and collaboration with the radiologist is key to the successful management of such cases. Though MRI is usually recommended only in recurrent fistula cases, ${ }^{27}$ the present study demonstrates that MRI is also indicated in cases where the IO cannot be accurately located using conventional methods.

There are a few limitations in this study. Anal manometry was not done. The availability of manometry for evaluating continence status would have led to a better evaluation than objective incontinence scoring.

\section{Conclusion}

The protocol suggested to manage anal fistulas with unlocatable internal openings seems quite effective. The healing and the incontinence rates in this group using this protocol were similar to fistulas in which the internal opening was found. Therefore, this protocol may be recommended in fistulas in which the internal/primary opening cannot be located by conventional methods and advanced radiological modalities. Further studies would confirm these findings.

\section{Presentation}

The abstract of this paper has been accepted for presentation at the annual meeting of the American Society of Colon and Rectal Surgeons (ASCRS) on 26 April, 2021 to be held in San Diego, USA.

\section{Acknowledgment}

We thank Dr Sushil Dawka, MS ELS, Professor of Surgery, SSR Medical College, Mauritius, for his help in editing and revising the manuscript.

\section{Funding}

Financial support: Nil.

\section{Disclosure}

The authors report no conflicts of interest for this work. 


\section{References}

1. Garcia-Aguilar J, Belmonte C, Wong WD, et al. Anal fistula surgery. Factors associated with recurrence and incontinence. Dis Colon Rectum. 1996;39(7):723-729. doi:10.1007/BF02054434

2. Sygut A, Mik M, Trzcinski R, et al. How the location of the internal opening of anal fistulas affect the treatment results of primary transsphincteric fistulas. Langenbecks Arch Surg. 2010;395(8):1055-1059. doi:10.1007/s00423-009-0562-0

3. Mei Z, Wang Q, Zhang Y, et al. Risk Factors for Recurrence after anal fistula surgery: A meta-analysis. Int J Surg. 2019;69:153-164. doi:10.1016/j.ijsu.2019.08.003

4. van Koperen PJ, Wind J, Bemelman WA, et al. Fibrin glue and transanal rectal advancement flap for high transsphincteric perianal fistulas; is there any advantage? Int $J$ Colorectal Dis. 2008;23 (7):697-701. doi:10.1007/s00384-008-0460-x

5. Emile SH, Khan SM, Adejumo A, et al. Ligation of intersphincteric fistula tract (LIFT) in treatment of anal fistula: an updated systematic review, meta-analysis, and meta-regression of the predictors of failure. Surgery. 2020;167(2):484-492. doi:10.1016/j.surg.2019.09. 012

6. Walega P, Romaniszyn M, Nowak W. VAAFT: a new minimally invasive method in the diagnostics and treatment of anal fistulasinitial results. Pol Przegl Chir. 2014;86(1):7-10. doi:10.2478/pjs2014-0002

7. Zhao B, Wang Z, Han J, et al. Long-term outcomes of ligation of the inter-sphincteric fistula tract plus bioprosthetic anal fistula plug (LIFT-Plug) in the treatment of trans-sphincteric perianal fistula. Med Sci Monit. 2019;25:1350-1354. doi:10.12659/MSM.914925

8. Prosst RL, Joos AK, Ehni W, et al. Prospective pilot study of anorectal fistula closure with the OTSC Proctology. Colorectal Dis. 2015;17(1):81-86. doi:10.1111/codi.12762

9. Kleinubing H Jr, Jannini JF, Campos AC, et al. The role of transperineal ultrasonography in the assessment of the internal opening of cryptogenic anal fistula. Tech Coloproctol. 2007;11(4):327-331. doi:10.1007/s10151-007-0375-5

10. Moscowitz I, Baig MK, Nogueras JJ, et al. Accuracy of hydrogen peroxide enhanced endoanal ultrasonography in assessment of the internal opening of an anal fistula complex. Tech Coloproctol. 2003;7 (3):133-137. doi:10.1007/s10151-003-0024-6

11. Garg P. Transanal opening of intersphincteric space (TROPIS) A new procedure to treat high complex anal fistula. Int $J$ Surg. 2017;40:130-134. doi:10.1016/j.ijsu.2017.02.095

12. Garg P. Understanding and treating supralevator fistula-in-ano: MRI analysis of 51 cases and a review of literature. Dis Colon Rectum. 2018;61(5):612-621. doi:10.1097/DCR.0000000000001051

13. Garg P, Kaur B, Menon GR. Transanal Opening of the Intersphincteric Space (TROPIS) procedure for high complex anal fistulas: long-term follow-up of 325 patients. Colorectal Dis. 2020.
14. Garg P. A new understanding of the principles in the management of complex anal fistula. Med Hypotheses. 2019;132:109329. doi:10.10 16/j.mehy.2019.109329

15. Garg P. Multiple openings in the anterior abdominal wall draining pus for a decade. Gastroenterology. 2017;153(5):e12-e13. doi:10.10 53/j.gastro.2017.03.057

16. Vaizey CJ, Carapeti E, Cahill JA, et al. Prospective comparison of faecal incontinence grading systems. Gut. 1999;44(1):77-80. doi:10.1136/gut.44.1.77

17. Plaikner M, Loizides A, Peer S, et al. Transperineal ultrasonography as a complementary diagnostic tool in identifying acute perianal sepsis. Tech Coloproctol. 2014;18(2):165-171. doi:10.1007/s10151013-1031-x

18. Nagendranath C, Saravanan MN, Sridhar C, et al. Peroxide-enhanced endoanal ultrasound in preoperative assessment of complex fistula-inano. Tech Coloproctol. 2014;18(5):433-438. doi:10.1007/s10151013-1067-y

19. Benjelloun EB, Souiki T, El Abkari M. Endoanal ultrasound in anal fistulas. Is there any influence on postoperative outcome? Tech Coloproctol. 2014;18(4):405-406. doi:10.1007/s10151-012-0967-6

20. Schwartz DA, Wiersema MJ, Dudiak KM, et al. A comparison of endoscopic ultrasound, magnetic resonance imaging, and exam under anesthesia for evaluation of Crohn's perianal fistulas. Gastroenterology. 2001;121(5):1064-1072. doi:10.1053/gast.2001.28 676

21. Siddiqui MR, Ashrafian H, Tozer P, et al. A diagnostic accuracy meta-analysis of endoanal ultrasound and MRI for perianal fistula assessment. Dis Colon Rectum. 2012;55(5):576-585. doi:10.1097/ DCR.0b013e318249d26c

22. Garg P. Is fistulotomy still the gold standard in present era and is it highly underutilized?: an audit of 675 operated cases. Int J Surg. 2018;56:26-30. doi:10.1016/j.ijsu.2018.06.009

23. Cirocco WC, Reilly JC. It is time to retire goodsall's rule: the midline rule is a more accurate predictor of the true and natural course of anal fistulas. Tech Coloproctol. 2020;24(4):317-321. doi:10.1007/s10151020-02167-z

24. Beavis RE. Use of hydrogen peroxide to identify internal opening of anal fistula and perianal abscess. Aust N Z J Surg. 1987;57(2):137.

25. Pinsk I, Seppala R, Friedlich MS. Anography: a technique for determining the location of the internal opening in perianal fistula. Colorectal Dis. 2010;12(9):896-900.

26. Holzer B, Rosen HR, Urban M, et al. Magnetic resonance imaging of perianal fistulas: predictive value for Parks classification and identification of the internal opening. Colorectal Dis. 2000;2(6):340-345. doi:10.1046/j.1463-1318.2000.00181.x

27. Garg P, Sodhi SS, Garg N. Management of complex cryptoglandular anal fistula: challenges and solutions. Clin Exp Gastroenterol. 2020;13:555-567. doi:10.2147/CEG.S198796
Clinical and Experimental Gastroenterology

\section{Publish your work in this journal}

Clinical and Experimental Gastroenterology is an international, peerreviewed, open access, online journal publishing original research, reports, editorials, reviews and commentaries on all aspects of gastroenterology in the clinic and laboratory. This journal is indexed on American Chemical Society's Chemical Abstracts Service (CAS).
The manuscript management system is completely online and includes a very quick and fair peer-review system, which is all easy to use. Visit http://www.dovepress.com/testimonials.php to read real quotes from published authors. 